\title{
Corona Perspectives - Philosophical Lessons from a Pandemic
}

In Europe and North America people sometimes speak of a stress-test while in China the pandemic has been likened to a zhaoyaojing or magic mirror in which people can see themselves for who they really are, fools or spirits, good and bad. The pandemic is a challenge to people, governments, and political systems in which many of their problems and characters are revealed. Our ways of inhabiting a sociotechnical world or technosphere come more clearly into view.

As three philosophers of technology from different parts of the world who have been together at Renmin University in Beijing, we have been collecting salient observations and present here a summary view that suggests the relevance of the philosophy of technology to an understanding of the Corona pandemic - SARS-CoV-2, COVID-19 and the various responses to it. ${ }^{1}$

Though we draw on the experience of COVID-19 in our respective countries, the goal is not to identify similarities and differences. The overtly political stories are familiar enough and in good hands with journalists, political theorists and opinionleaders. In these stories, the order of explanation proceeds from culture, ideology, and political systems to the Chinese way of managing the pandemic, German efficiency, or the American state of violence and confusion. This order of explanation is turned around when the story becomes one of a technical challenge in need of an epidemiological response. From this perspective, what we witness in different countries are variants of the same type of action - similar predicaments and adjustments but very different kinds of responses. When the order of explanation puts the problem of technical management first, it is not always clear what the alternatives are, how to deliberate the issues, and what it all means with regards to people, nature, and society. The vocabulary of power and politics, ideology and theories of governance is not sufficient to open the black box of Sachzwang or technical exigency. In respect to technological and technocratic dimensions of the pandemic, we thus want to do as philosophers do - pursue self-understanding even as we gaze into the hall of mirrors which is the pandemic on an international scale.

1 This is extracted from a longer work-in-progress. Criticism and commentary are welcome to help will improve an eventual larger publication. An intermediary version was published as Liu, Yongmou; Mitcham, Carl; Nordmann, Alfred (2021): 全球疫情技治的文化比较 (Cultural Comparison of Global Technical Governance of COVID-19), in: 科学·经济·社会 (Science. Economy $\cdot$ Society), Bd 39:1, 1-12. 
I. The predominant tone of public discussion reflects a technological, perhaps technocratic mindset according to which the 'Corona Crisis' is defined in technical and managerial terms. It calls for an effective response to the virus and the 'logic of exponential spreading' - how to flatten the curve, how to trace and break chains of infection, how to keep the economy going, how to adjust the capacities of the health care system.

II. Philosophers and political theorists ordinarily emphasize differences in cultural traditions and public values, since this is their frame of analysis. As philosophers of technology we approach the current situation from the point of view of technical action - we see societies struggling with the enormous practical problem of managing the pandemic, simultaneously yielding to and struggling - even rebelling - against a technocratic mindset that appears divorced from and opposed to the sphere of politics and the discussion of public values.

III. Whether subtly subversive or violently antagonistic, questioning of what needs to be done and any discussion of alternatives represents a shift of register which is disruptive of the technical brief to protect the general population from the uncontrolled spread of the virus.

IV. We identify three technological paradigms or forms of technical intelligence. Grand-scheme optimizing evokes the procedures of numerical governance through state bureaucracies as well as $19^{\text {th }}$ century population science (Bevölkerungswissenschaft). It treats all members of the body politic as risk-bearing nodes whose system interactions need to be managed, whereas patchwork satisficing draws on many sources of popular knowledge which do not provide total control but which work redundantly together to significantly lower the risk of infection. As such, patchwork satisficing is akin to citizen science (Bürgerwissenschaft). Thirdly, there is omnipresent locally distributed monitoring and management which develops and deploys knowledge and tools as fire departments do: Where an outbreak occurs, the fire will be extinguished and chains of infection broken through real-time responsiveness. Though these forms of intelligence compete with one another, they are not openly discussed as such. The contest among them becomes manifest only as priorities change, policies adapt and responsibility is shifted among the various actors.

V. The three approaches correspond to three practical attitudes for dealing with uncertainty. Many people prefer to err on the side of caution by adopting a strategy of rigorous risk-avoidance (grand-scheme optimizing), others are willing to take their chances as they adopt precautions and judge the risk to be within reasonable limits of acceptability (patchwork satisficing), yet others revise their risk-behavior in a real-time feedback-loop that permanently assesses measures taken and current trends (real-time responsiveness). One way of challenging the technological framing of the 'Corona crisis' is to deny the reality of uncertainty 
and risk. One might call this a form of defection - getting away from those who see a problem and thereby, in some cases, from the mainstream of society.

VI. The three approaches also differ in that grand-scheme optimizing takes us back to administrative practices of the state, to thermodynamics, gas laws, statistical population science (Bevölkerungswissenschaft) especially of the $19^{\text {th }}$ century and thus also to a particular regime of knowledge/power which elevates scientists like Christian Drosten, Anthony Fauci, and Nanshan Zhong to the rank of national celebrities and authorities. From the point of view of Science and Technology Studies (STS), constructive technology assessment, co-design, open science and open innovation, it was astounding to see how swiftly in a moment of crisis our modern knowledge-societies reverted to a supposedly outdated model. Though the contribution of citizens and 'citizen science' came back in with patchwork satisficing and real-time responsiveness, this did not owe to discussions about the best ways of mobilizing widely distributed competence in $21^{\text {st }}$ century societies.

VII. The common-place technology of 'everyday masks (Alltagsmasken)' is viewed differently and is subject to differential contestation by the various approaches. Their usefulness and efficacy were at first denied and then redeemed in the concert of redundant measures. At the same time they are symbolically efficacious, signifying solidarity, acquiescence, or collusion in the national project of 'fighting the pandemic.' Inversely, the hygiene technology of disinfection has been carried along in a mostly unquestioned and unfounded way, grounded in public health habits which seemingly empower each individual. Contested in quite a different way are the various statistical and dashboard technologies that inform and communicate only relative to pre-established technical goals.

VIII.Everyone everywhere inhabits a technosphere that evolves and gradually changes over time. It is a form of life by which we coordinate human and technical relations. The pandemic is unsettling due to the subtle ways in which it subverts established forms of life. There is the handshake by which people are formally appointed to their office, deals are sealed, and commitments are made. It is being replaced by an awkward touching of elbows or the polite bow. Family life and neighborhood interactions are reorganized not around seeing but around avoiding each other. Entering the public sphere, one is no longer expected to show one's face. As with HIV/AIDS in the 1980s or the SARS experience in 2003, these are not small adjustments which reflect new opinions or beliefs. They profoundly reconfigure human relations. In the world of AIDS, sex is not what it used to be. In the new normality of Corona, how will we face each other?

IX. With Daniel Defoe (Journal of the Plague Year), Albert Camus (La Peste), or Bertolt Brecht („Radwechsel“ or „Changing the Wheel“) we can describe the 
technocratic Corona condition as one of being exiled at home and impatient of the present. The loss of a future and of the past amount to a loss of the political - all that is left of it is a kind of rearing up or rebelliousness against the rule of necessity. In the times of pestilence and plague and a technocratic condition, we lose the power to imagine another world for ourselves, or only at the price of willfully disregarding the demands of the present. It is not necessary, however, to view this 'imprisonment' in terms of prohibitions. It should be possible to consider the apparent prohibitions as limits that constitute a space for transformative change. Social distancing, for example, is a means for lowering the rate of infections. At the same it might be a means for keeping our cool and avoiding the kind of tragedy that results from overheated emotions. We are reminded of Boccaccio (Decamerone) who discovered the pleasure of story telling when escaping the Black Death of Florence in 1350 and opened the door to the Renaissance.

X. The response to the pandemic does not in and of itself hold any promise of transformative change towards a decelerated, sustainable, more equitable world. Much rather, it holds the danger that the tension will rise between the socalled 'reasonable' people who exercise solidarity by acknowledging technical necessities and a somewhat reckless, rebellious populism which claims for itself the evacuated sphere of politics by invoking liberty and human rights. If at all, this tension can be mitigated by a moderated technocracy that tends to the available technical and managerial choices, by keeping in mind that the interventions to maintain a way of life involve an ideal of the good life now and in the future.

Within a world governed by Sachzwang or technical necessity, there is much more going on than meets the eye when one looks at societies, politics, cultures, or ideologies. Our ten points suggest as much. Even as we become aware of different technological paradigms, of alternative designs, of opportunities for re-organization, we remain within the sphere of what needs to be done, producing a tension to the sphere of willful politics and self-determination. If we are right, this predicament inescapably presents itself just as soon as a "Corona crisis" is pronounced.

Of course, we also observe a considerable spectrum in the ways the tension plays out in our three and other societies. In China, perhaps it has been accommodated by a moderated technocracy that incorporates the idea of technical necessity within a sense of public virtue and national identity. In Germany, it takes considerable work to maintain a purely managerial mode of politics, while soft-spoken restlessness and unruly protest have been leading to open battle in in US-American streets. Only time will tell whether this kind of analysis is helpful - uncovering the underlying predicament, foregrounding the reconfiguration of human relations in a pandemic technosphere, shifting attention towards the micropolitics of technological crisis-management. 